\title{
Analysis on the Threshold Effect of the Factors Affecting the Relationship between China's Economic Growth and Carbon Emission
}

\author{
Yi Wang \\ North China Electric Power University \\ Beijing, China \\ wy6060@126.com
}

\author{
Minghao XU \\ North China Electric Power University \\ Beijing, China \\ haogegeshishui@163.com
}

\author{
Jingjing Lu \\ North China Electric Power University \\ Beijing, China \\ Lujingjing9126@163.com
}

\begin{abstract}
China's rapid economic growth has brought many environmental problems, and the rapid growth of carbon emission attracts more and more people's attention, so the research on the relationship between economic growth and carbon dioxide emission is increasingly important. Based on the threshold panel model developed by Hansen, this paper chooses the provincial panel data from 1995 to 2014 and analyzes the influence of energy intensity, environmental regulation and the introduction of foreign capital on the relationship between economic growth and carbon emission. The results show that there is a significant nonlinear relationship between them, there is double threshold of energy intensity, single threshold of environmental regulation, and there is no threshold for foreign capital introduction. Through the results of the factors' threshold effect, then we give some reasonable suggestions.
\end{abstract}

Keywords—economic growth; carbon emission; threshold effect; panel

\section{INTRODUCTION}

Since the reform and opening-up, China's industrialization has entered a period of rapid development. Driven by industrialization and urbanization, China's economic growth has made remarkable achievements in the world. But for a long time, in exchange for high growth of the extensive economic development model that relies on high input and high consumption has made China's energy consumption and carbon dioxide emissions increased rapidly. According to BP World Energy, China's energy consumption reached to 3.01 billion tons by 2015, with $\mathrm{CO}_{2}$ emissions reaching to 9.15 billion tons, accounting for $23 \%$ and $27 \%$ of the world's total respectively. As the country with largest energy consumption and carbon dioxide emissions in the world, China faces a internal huge pressure on energy-saving emission reduction and the growing international pressure on public opinion. Since 2010, the whole China has gone into the late industrialization, the economic structure has been constantly optimized, the tertiary industry has gradually become the main consumer demand, the economic growth rate has changed from high-speed growth to low growth, and China's economy has turned to "new normal". In the economic "new normal", as soon as possible to achieve economic growth and the carbon dioxide emissions reduction, taking a green, low-carbon sustainable development path is the only way for the future development of China's industrialization.

At present, the relationship research about economic growth and carbon dioxide emissions mainly focus on two aspects: One is the Inverted "U" relationship between economic growth and carbon dioxide emissions, the other is causal relationship between the two. In 1991, Grossman and Krueger studied the impact of North American trade agreements on environmental quality, and found the concentrations of two air pollutants (sulfur dioxide and soot) increased with the per capita GDP growth at first, then concentrations showed a downward trend[1]; In 1993, Panayotou called the relationship of "inverted $U$ " as environmental Kuznets curve (EKC) by borrowing the inverted "U" curve of Kurossez's unequal distribution of income[2]. Many scholars used one or more countries to verify the relationship between carbon dioxide emissions and per capita GDP, but the conclusions of different researchers were not the same. For example, researchers such as Hamit-Haggar M(2012) supported that there was an inverted " $U$ " type curve between the two[3], but some scholars like Friedl and Getzner (2003) found that there was an inverted " $N$ " relationship[4], what's more, many researchers also found there was no specific relationship between the two.

Econometrics is mainly used on the verification of the causal relationship. There are many Causality studies based on Linearity, in foreign countries, Soheila Khoshnevis Yazdi et al.(2014) showed a bidirectional causality running between GDP and $\mathrm{CO}_{2}$ emissions in the short-run dynamics and a unidirectional causality running from GDP to $\mathrm{CO}_{2}$ emissions in the Long-run dynamics by using cointegration and unit root tests[5]; Mohammad Salahuddin et.al(2015) applied Granger 
causality test and showed there was a bidirectional causal link between economic growth and $\mathrm{CO}_{2}$ emissions[6]. There are also a large number of literature apply the causality test to study the relationship between GDP and $\mathrm{CO}_{2}$ emissions in domestic. S Peng and Z Sun(2010) investigated the long run Granger causality relationship between economic growth, energy consumption and carbon dioxide emissions in China during the period 1952-2007, and suggest that there was bidirectional causality running between GDP and $\mathrm{CO}_{2}$ emissions in the long run[7]; Shaojian Wang et.al(2015) analyzed the cointegrating, temporally dynamic, and casual relationships by using data for the period 1990-2012, and found the Granger causality and cointegration relationship were among the variables[8]. Some causality researches also based on non-linear method, for instance, Ozturk and acaravci(2013) used non-linear elasticity F statistic to analyze the cointegration relationship between energy consumption, economic growth and carbon emissions during the period 1960-2007[9]. The results showed that the impact from GDP to $\mathrm{CO}_{2}$ emissions was not significant, and so on.

The relationship between carbon dioxide emissions and economic growth has a strong policy application value, but the above studies only tended to focus on the relationship verification between economic growth and carbon dioxide emissions, so ignored the other factors on the relationship between the two. Considering this problem, Dengxun Jia and Jie Huang(2015) studied the nonlinear relationship between economic growth and carbon emissions and its formation mechanism, the results showed that there was a significant threshold effect of industrial structure, technological level and energy consumption structure in the relationship between economic growth and carbon emissions. When these threshold variables met or exceed a certain threshold, the relationship between economic growth and carbon emissions will change significantly[10]. That is to say, the relationship between economic growth and carbon dioxide emissions may change due to different factors. This paper takes the imbalance of regional economic development of China into account, using the provincial panel data to analysis the mechanism of energy intensity, environmental regulation and the introduction of foreign investment to the relationship between economic growth and carbon emissions.

The rest of the arrangement is as follows: Section 2 is the methodology, which introduces the panel threshold regression model. Section 3 is the data description, which mainly introduces the data index and source used in this paper. Section 4 is the empirical results and analysis. And the last part is the conclusion of the study.

\section{THRESHOLD MODEL SETTING}

In this paper, the panel threshold regression model developed by Hansen (1999) is an extension of the truncated regression test method, and the limitation of Chow's segmentation regression has been improved. The outstanding advantage is that it does not need the form of a given nonlinear equation. The threshold value and its number are completely burned by the sample data decision. The method is that the model is divided into two or more intervals by threshold level, and there is a difference in the regression expression of each interval. The basic idea is to assume that there is a threshold level $T h$, so that when the threshold variable $q_{i, t} \leq T h$ and $q_{i, t}>T h$, the impact of economic growth on carbon emission will be significantly different. We set the virtual display variable $I$. The sample interval can be divided into two different intervals depending on whether the threshold variable $q_{i, t}$ exceeds the threshold $T h$, and different values are used for them. Then a panel threshold regression model with a single threshold can be expressed as follow:

$$
\text { Pollution }_{i, t}=c+w_{1} P G D P_{i, t}{ }^{*} I\left(q_{i, t} \leq T h\right)+w_{2} P G D P_{i, t}{ }^{*} I\left(q_{i, t}>T h\right)
$$

Where $q_{i, t}$ is the threshold variable, Th is the specific threshold, $w_{1}$ and $w_{2}$ are the threshold variable $q_{i, t}$ respectively when $q_{i, t} \leq T h$ and $q_{i, t}>T h$. The core interprets coefficient of influence of the variable $P G D P_{i, t}$ on the explanatory variable Pollution $_{i, t}$, and the meaning of the other variable is unchanged. If the threshold $T h$ is selected so that the segmented form of the model is appropriate, the model will achieve better results. OLS is directly evaluated for Eq.(1) to obtain the sum of squares of residuals: $S(T h)=\hat{e}(T h)^{\prime} \hat{e}(T h)$. Then the estimated value of the threshold should be: $\hat{T h}=\arg \min S(T h)$, the smallest of the sum of the squared sum $S(T h)$ is the estimated threshold value $\hat{T h}$. We need to carry out the hypothesis test after getting the estimated value $\hat{T h}$, and assuming that the test consists of two parts: first check whether the threshold effect is significant; second test threshold and the true value is equal.

Firstly, the significance of the threshold affect test. The purpose is to test the two sets of samples divided by threshold. The model estimates whether the parameters $w_{1}$ and $w_{2}$ are significantly different. If there is no significant difference between the two, the model does not show significant threshold characteristics. The original hypothesis of the test is $H_{0}: w_{1}=w_{2}$, the alternative is assumed to be $H_{1}: w_{1} \neq w_{2}$, and the $\mathrm{F}$ statistic of the test is :

$$
F=\frac{S_{0}-S(\hat{T h})}{\hat{\sigma}^{2}}
$$

Where $S_{0}$ is the sum of squares of residuals under the original hypothesis, $S(\hat{T h})$ is the sum of squares of residuals with threshold effect, and $\hat{\sigma}^{2}=S(\hat{T h}) / n(T-1)$ is the uniform estimate of the variance of the disturbance term. However, this F-statistic test will encounter a serious obstacle that is not recognized under the original hypothesis. It will cause the traditional test statistic so that its large sample is not a "chisquare distribution" but a "non-standard" Distribution ", and the distribution of the critical value can't be obtained in a simulated manner. To overcome this problem, Hansen (1999) transforms the large sample distribution function of the 
statistics itself to obtain the progressive $p$ value of the large sample. In the original hypothesis, the large sample of the pvalued statistic is uniformly distributed, and the critical value can be calculated by the "bootstrap", then the corresponding pvalue is obtained based on the maximum likelihood method LR. If the $p$ value is small enough, we will reject the original hypothesis $H_{0}$, indicating that there is a significant threshold effect at this time.

Secondly, verifying that the threshold is equal to the true value. Hansen (1999) pointed out that the threshold estimate is consistent with the true value when the threshold effect exists, but at this time due to the existence of interference parameters will make the asymptotic distribution highly non-standard state. Hansen (1999) used the maximum likelihood method to check the threshold Th and obtain the asymptotic distribution of the statistic. The original hypothesis of the test is $H_{0}: \hat{T h}=T h$, and the corresponding likelihood ratio statistic is:

$$
L R=\frac{S(T h)-S(\hat{T h})}{\hat{\sigma}^{2}}
$$

The corresponding p value can be obtained according to the LR test. If the $\mathrm{p}$ value is large enough, the original hypothesis $H_{0}$ is accepted, indicating that the threshold estimate is equal to the true value at this time.

The above is only for the existence of a threshold value of the situation, but in fact there may be two or more threshold. If there are two thresholds, then we can set the double threshold regression model as:

$$
\begin{aligned}
& \text { Pollution }=c+w_{1} P G D P_{i, t}{ }^{*} I\left(q_{i, t} \leq T h_{1}\right) \\
& +w_{2} P G D P_{i, t}{ }^{*} I\left(T h_{1} \leq q_{i, t} \leq T h_{2}\right) \\
& +w_{3} P G D P_{i, t}{ }^{*} I\left(q_{i, t}>T h_{2}\right)
\end{aligned}
$$

The multiple threshold model can be extended on the basis of a single and double threshold model. Its estimation idea is roughly the same as above, and the estimation is continued until the threshold is no longer significant.

\section{DATA SOURCES}

This paper chooses the panel data of 29 provinces and autonomous regions in China in addition to Tibet in the period from 1995 to 2014. In order to ensure the true reliability of the data, Sichuan and Chongqing will be transformed into the same area. The actual per capita GDP (based on 1995) which is better able to reflect the level of economic development than GDP is used to measure economic growth. Reflecting the impact of real income levels on carbon dioxide emission, all data comes from provinces and municipal statistical yearbook. So far, China has no agencies to provide data on the amount of carbon dioxide emission from provinces and cities, this paper uses China Energy Statistics Yearbook to provide the terminal energy consumption in the physical scale provided in the 15 kinds of terminal energy varieties of data projections of various provinces and cities of carbon dioxide emission. Calculated as follow:

$$
C E=\sum_{i=1}^{n} E C_{i} \times C E F_{i} \times 44 / 12
$$

$C E$ is the amount of carbon dioxide; $E C_{i}$ is the amount of energy consumption (in terms of heat); $C E F_{i}$ is the carbon emission factor corresponding to the i-th energy; 44/12 is the carbon emission factor is converted to carbon dioxide emission factor, emission equivalent is to $44 / 12$ (about equal to 3.67) of carbon dioxide emission.

Energy intensity (Enintensity), environmental regulation (Er) and foreign investment (Fdi) are used as threshold variables to study their influence on the mechanism of the relationship between carbon dioxide emission and economic growth. Which environmental regulation using the proportion of investment in industrial pollution in each region accounted for the second output value.

\section{EMPIRICAL ANALYSIS}

\begin{tabular}{|c|c|c|c|c|c|c|}
\hline $\begin{array}{c}\text { Threshold } \\
\text { variable }\end{array}$ & No. & $\begin{array}{c}\text { Threshold } \\
\text { value }\end{array}$ & $\begin{array}{c}95 \% \\
\text { Lower }\end{array}$ & $\begin{array}{c}95 \% \\
\text { Upper }\end{array}$ & $\mathbf{F}$ & prob \\
\hline \multirow{3}{*}{ Enintensity } & Th1 & $0.5756 * * *$ & 0.5074 & 0.5868 & 81.48 & 0.000 \\
\hline & Th2 & $0.7517 * * *$ & 0.7395 & 0.7714 & 91.51 & 0.000 \\
\hline & Th3 & 1.0921 & 1.0785 & 1.1202 & 82.96 & 0.650 \\
\hline \multirow{3}{*}{ Er } & Th1 & $-1.1149 * *$ & -1.1869 & -1.1058 & 19.80 & 0.030 \\
\hline & Th2 & -0.9647 & -0.9754 & -0.9477 & 4.11 & 0.780 \\
\hline & Th3 & -0.8083 & -0.8209 & -0.7928 & 2.65 & 0.740 \\
\hline \multirow{3}{*}{ FDI } & Th1 & 9.7981* & 9.6068 & 9.8798 & 33.34 & 0.130 \\
\hline & Th2 & 10.1887 & 10.0481 & 10.2948 & 21.53 & 0.290 \\
\hline & Th3 & 14.1026 & 13.6735 & 14.1887 & 9.99 & 0.790 \\
\hline
\end{tabular}

In this paper, energy intensity, environmental regulation and foreign investment are introduced as threshold variables. The significance test results are shown in TABLE I:

TABLE I. PANEL THRESHOLD EFFECTIVENESS TEST

Note: The asterisk represents the significance of the threshold (p value), *** $\mathrm{p}$ $<0.01, * * \mathrm{p}<0.05, * \mathrm{p}<0.1$.

It can be seen from the table. 1 that there is a double threshold of energy intensity at $1 \%$ significance level, environmental regulation has a single threshold at $5 \%$ significance level, and there is no threshold for foreign capital introduction. The original data has been logarithmic processed in the process of analysis, and the actual threshold estimation results are as TABLE II:

TABLE II. THRESHOLD VALUE ESTIMATION RESULTS

\begin{tabular}{|c|c|c|c|}
\hline $\begin{array}{c}\text { Threshold } \\
\text { variable }\end{array}$ & $\begin{array}{c}\text { The number of } \\
\text { threshold }\end{array}$ & $\begin{array}{c}\text { estimated } \\
\text { value }\end{array}$ & $\begin{array}{c}\mathbf{9 5 \%} \text { confidence } \\
\text { interval }\end{array}$ \\
\hline Enintensity & Double & 1.7782 & {$[1.6610,1.7982]$} \\
\cline { 3 - 4 } & Single & 2.1206 & {$[2.0949,2.1628]$} \\
\hline Er & 0.3279 & {$[0.3052,0.3309]$} \\
\hline
\end{tabular}

In order to understand the performance of different threshold variables in different industrial development levels, this paper divides 29 provinces into five regions according to the method of Chen (2012):

- Group1: Beijing, shanghai;

- Group2: Tianjin, Jiangsu, Zhejiang, Guangdong; 
- Group3: Neimenggu, Liaoning, Jilin, Fujian, Shandong;

- Group4: Hebei, Heilongjiang, Anhui, Jiangxi, Henan, Hubei, Hunan, Shanxi, Sichuan Chongqing, Qinghai, Ningxia;

- Group5: Shanxi, Guangxi, Guizhou, Yunnan, Gansu, Hainan, Xizang, Xinjiang.

We set the energy intensity of the double threshold, the environmental regulation of the single threshold. The panel threshold regression analyses of the results are shown in TABLE III:

TABLE III. GROUPING PANEL THRESHOLD REGRESSION RESULTS

\begin{tabular}{|l|c|c|c|c|c|}
\hline \multirow{2}{*}{ COEFFICIENT } & $\mathbf{( 1 )}$ & $\mathbf{( 2 )}$ & $\mathbf{( 3 )}$ & $\mathbf{( 4 )}$ & $\mathbf{( 5 )}$ \\
\cline { 2 - 6 } & Group1 & Group2 & Group3 & Group4 & Group5 \\
\cline { 2 - 6 } & Pollution & Pollution & Pollution & Pollution & Pollution \\
\hline PGDP & $0.5560^{* * *}$ & $1.1909^{* * *}$ & $1.1190^{* * *}$ & $1.2971^{* * *}$ & $1.3269^{* * *}$ \\
\hline (EI $\leq$ Th1) & $(0.118)$ & $(0.044)$ & $(0.026)$ & $(0.028)$ & $(0.034)$ \\
\hline PGDP & $0.5379^{* * *}$ & $1.1973^{* * *}$ & $1.1552^{* * *}$ & $1.3261^{* * *}$ & $1.3591^{* * *}$ \\
\hline (Th1<EI $\leq$ Th2) & $(0.125)$ & $(0.048)$ & $(0.028)$ & $(0.030)$ & $(0.036)$ \\
\hline PGDP & $0.5711^{* * *}$ & $1.2163^{* * *}$ & $1.1897^{* * *}$ & $1.3643^{* * *}$ & $1.3898^{* * *}$ \\
\hline (EI>Th2) & $(0.130)$ & $(0.052)$ & $(0.031)$ & $(0.032)$ & $(0.039)$ \\
\hline Constant & $2.8653^{* *}$ & $-2.7611^{* * *}$ & $-1.6976^{* * *}$ & $-3.3020^{* * *}$ & $-3.6593^{* * *}$ \\
\hline \multicolumn{7}{|c|}{ Threshold variable: ER } \\
\hline PGDP & $(1.259)$ & $(0.476)$ & $(0.258)$ & $(0.275)$ & $(0.320)$ \\
\hline (ER $\leq$ Th1) & $0.6469^{* * *}$ & $1.1127^{* * *}$ & $0.9959^{* * *}$ & $1.1298^{* * *}$ & $1.2800^{* * *}$ \\
\hline PGDP & $(0.074)$ & $(0.028)$ & $(0.027)$ & $(0.026)$ & $(0.035)$ \\
\hline (ER>Th1) & $0.6651^{* * *}$ & $1.1253^{* * *}$ & $1.0137^{* * *}$ & $1.1383^{* * *}$ & $1.2758^{* * *}$ \\
\hline Constant & $(0.078)$ & $(0.029)$ & $(0.029)$ & $(0.027)$ & $(0.034)$ \\
\hline \multicolumn{7}{|c|}{$1.8627^{* *}$} & $-1.9085^{* * *}$ & -0.3388 & $-1.4952^{* * *}$ & $-2.8841^{* * *}$ \\
\hline
\end{tabular}

Note: Parentheses represent standard deviations, ${ }^{* * *} \mathrm{p}<0.01,{ }^{* *} \mathrm{p}<0.05$, ${ }^{*} \mathrm{p}$ $<0.1$.

From the results of the group analysis, it can be seen that the energy intensity of all groups has a double threshold at the $1 \%$ significance level, and the environmental regulation has a single threshold at the $1 \%$ significance level. However, the threshold and economic growth coefficients of different groups are different. We can analyze the relationship between carbon emission and economic growth in different regions based on these differences.

The two threshold of energy intensity divide three intervals. The panel threshold regression results show that all groups under the GDP growth environment have been basically improved in the process of energy intensity decline and effectively reducing the carbon emission. Indicating that carbon emission is mainly caused by energy consumption and it can be improved by reduced energy intensity. In addition to the regional one, the other areas in different threshold of the per capita GDP growth brought about by the environmental pollution problems are relatively large, and the coefficient is more than 1 . It shows that with the further development of the economy and the further improvement of the degree of industrialization, the energy costs and environmental costs will be further expanded until it can't bear. So the industrial development model these parts are unsustainable. From the results of environmental regulation, in addition to the regional five in the case of increased environmental regulation, carbon emission has been reduced. And the effect is not great; other areas have not been improved. This shows that increasing the intensity of environmental regulation can't improve the efficiency of carbon emission largely; even it may not have a good effect. Therefore, China should focus on the necessary adjustment of its industrial structure and development model.

\section{CONCLUSION}

From the above analysis, we can know that the intensity of environmental regulation can't effectively reduce carbon emission. China can reduce energy intensity appropriately to achieve rapid economic development in the process of carbon reduction. From the comparison of each group, the increase in the degree of industrialization makes the energy costs and environmental costs further expand. Therefore, China should strengthen its industrial structure and development model to make the necessary adjustments. We should vigorously promote the development of the tertiary industry and accelerate the construction of energy-saving industrial system to reduce the process of economic development in the carbon emission.

\section{REFERENCES}

[1] Grossman G M, Krueger A B. Environmental Impacts of a North American Free Trade Agreement[J]. Social Science Electronic Publishing, 1992,8(2):223-250.

[2] Panayotou T. Empirical Tests and Policy Analysis of Environmental Degradation at Different Stages of Economic Development[J]. Ilo Working Papers, 1993,4.

[3] Hamit-Haggar M. Greenhouse gas emissions, energy consumption and economic growth: A panel cointegration analysis from Canadian industrial sector perspective[J]. Energy Economics, 2012,34(1):358-364.

[4] Friedl B, Getzner M. Determinants of CO 2 emissions in a small open economy[J]. Ecological Economics, 2003,45(1):133-148.

[5] Yazdi S K, Shakouri B, Khanalizadeh B. The granger causality among tourist arrival, economic growth and $\mathrm{CO} 2$ emissions in Iran.[J]. Advances in Environmental Biology, 2014,8(13):632-637.

[6] Salahuddin M, Gow J, Ozturk I. Is the long-run relationship between economic growth, electricity consumption, carbon dioxide emissions and financial development in Gulf Cooperation Council Countries robust?[J] Renewable \& Sustainable Energy Reviews, 2015,51:317-326.

[7] Peng S, Sun Z. An econometric study of CO2, emissions, energy consumption and economic growth in $\mathrm{China}[\mathrm{C}] / /$ International Conference on Mechanic Automation and Control Engineering. IEEE, 2010:1805-1808.

[8] Wang S, Li Q, Fang C, Zhou C. The relationship between economic growth, energy consumption, and $\mathrm{CO} 2$ emissions: Empirical evidence from China.[J]. Science of the Total Environment, 2016, 542(Pt A):360371.

[9] Ozturk I, Acaravci A. The long-run and causal analysis of energy, growth, openness and financial development on carbon emissions in Turkey[J]. Energy Economics, 2013, 36(s 1-2):262-267.

[10] Dengxun Jia, Jie Huang. Threshold effect, carbon emissions and economic growth[J].soft,2015,(04):67-70. (In Chinese) 